\title{
The protein and lipid composition of the membrane of milk fat globules depends on their size
}

\author{
Jing Lu, ${ }^{*} † \ddagger ~ N u r i t ~ A r g o v-A r g a m a n, \S ~ J e n i ~ A n g g r e k,{ }^{*}$ Sjef Boeren, $†$ Toon van Hooijdonk, ${ }^{*}$ Jacques Vervoort, $†$ \\ and Kasper Arthur Hettinga*1 \\ *Dairy Science and Technology, Food Quality and Design group, Wageningen University, Bornse Weilanden 9, 6708 WG, \\ Wageningen, the Netherlands \\ †Laboratory of Biochemistry, Wageningen University, Dreijenlaan 3, $6703 \mathrm{HA}$, Wageningen, the Netherlands \\ †Institute of Agro-Products Processing Science and Technology, Chinese Academy of Agricultural Sciences (CAAS), 100193, Beijing, China \\ $\S$ Department of Animal Sciences, The Robert H. Smith Faculty of Agriculture, Food and Environment, The Hebrew University of Jerusalem, \\ Rehovot, 76100, Israel
}

\begin{abstract}
In bovine milk, fat globules (MFG) have a heterogeneous size distribution with diameters ranging from 0.1 to $15 \mu \mathrm{m}$. Although efforts have been made to explain differences in lipid composition, little is known about the protein composition of MFG membranes (MFGM) in different sizes of MFG. In this study, protein and lipid analyses were combined to study MFG formation and secretion. Two different sized MFG fractions $(7.6 \pm 0.9 \mu \mathrm{m}$ and $3.3 \pm 1.2 \mu \mathrm{m})$ were obtained by centrifugation. The protein composition of MFGM in the large and small MFG fractions was compared using mass-spectrometry-based proteomics techniques. The lipid composition and fatty acid composition of MFG was determined using HPLC-evaporative lightscattering detector and gas chromatography, respectively. Two frequently studied proteins in lipid droplet biogenesis, perilipin-2 and TIP47, were increased in the large and small MFG fractions, respectively. In the large MFG fraction, besides perilipin-2, cytoplasmic vesicle proteins (heat shock proteins, 14-3-3 proteins, and Rabs), microfilaments and intermediate filamentrelated proteins (actin and vimentin), host defense proteins (cathelicidins), and phosphatidylinositol were higher in concentration. On the other hand, cholesterol synthesis enzymes [lanosterol synthase and sterol-4a-carboxylate 3-dehydrogenase (decarboxylating)], cholesterol, unsaturated fatty acids, and phosphatidylethanolamine were, besides TIP47, higher in concentration in the small MFG fraction. These results suggest that vesicle proteins, microfilaments and intermediate filaments, cholesterol, and specific phospholipids play an important role in lipid droplet growth, secretion, or both. The observations from this study clearly demon-
\end{abstract}

Received September 10, 2015.

Accepted January 30, 2016.

${ }^{1}$ Corresponding author: kasper.hettinga@wur.nl strated the difference in protein and lipid composition between small and large MFG fractions. Studying the role of these components in more detail in future experiments may lead to a better understanding of fat globule formation and secretion.

Key words: milk, fat globule, membrane proteome, phospholipids, triglycerides

\section{INTRODUCTION}

Milk fat is secreted by the mammary gland in the form of globules. These milk fat globules (MFG) are composed of a lipid core (mainly triglycerides, $\mathbf{T g}$ ) covered by a 3-layer membrane structure called the milk fat globule membrane (MFGM, mainly phospholipids and proteins). In bovine milk, the diameter of the fat globules varies from $\sim 0.1$ to $\sim 15 \mu \mathrm{m}$. The composition of fatty acids and phospholipids varies between different sized MFG. For example, smaller MFG contained a higher amount of PUFA (Lopez and Menard, 2011; Mesilati-Stahy et al., 2011). It was also shown that the phospholipid composition of the MFGM varied between different MFG sizes (Cohen et al., 2015; Mesilati-Stahy et al., 2015). Although the differences in lipid composition have been studied in different sized MFG, little is known on the relation between MFG size and protein composition of the MFGM. The study of MFG size and composition has several industrial implications. For example, cheese characteristics (Michalski et al., 2003), as well as MFG coalescence (Lopez et al., 2010), were shown to be related to the protein and lipid composition of different sized MFG. In addition, different lipids have different metabolic fates in the human body (Michas et al., 2014), and differences in lipid composition depending on MFG size thus also have nutritional implications.

In the last few decades, improvements in the understanding of milk component synthesis and secretion were achieved (McManaman and Neville, 2003; Neill, 
2006). In the mammary gland, milk Tg are synthesized between the layers of the endoplasmic reticulum (ER) membrane and secreted into the cytoplasm as micro lipid droplets (LD). Part of these micro LD fuse to form large LD when moving to the apical plasma membrane. Via a special budding process, the LD are released from epithelial cells to milk as MFG. These MFG are covered by a 3-layer membrane structure (MFGM) that is derived from the outer leaflet of the ER and the apical plasma membrane of the cell. The MFGM is composed of phospholipids and proteins. Of the proteins in MFGM, butyrophilin, xanthine dehydrogenase, and perilipin-2 (ADFP) were shown to be involved in the budding process of MFG to milk (Mather and Keenan, 1998; Heid and Keenan, 2005; Dewettinck et al., 2008). The secretion of both smaller and larger LD results in the wide range of MFG sizes as found in milk. The mechanism that regulates formation and secretion of different sized LD from the mammary gland is, however, not well elucidated (Mather and Keenan, 1998).

Lipid droplets of different sizes can be found also in adipose (Hörl et al., 2011) and liver (Stringer et al., 2010) cells. Two main factors on the surface of LD, phospholipids and proteins, were suggested to control LD size (Cohen et al., 2015). For example, in murine adipocytes, the level of the PAT (perilipin/adipophilin/ adipose differentiation related proteins/TIP47) protein ADFP decreased simultaneously with a reduction in intracellular LD size upon dietary supplementation of trans-10,cis-12 CLA (Stringer et al., 2010). Enzymes increasing $\mathrm{Tg}$ synthesis or inducing $\mathrm{Tg}$ hydrolysis have also been suggested to regulate LD size (Thiam et al., 2013). The protein activity on the LD surface was hypothesized to be changed by interactions with specific phospholipids (Walther and Farese, 2009). Phospholipids in the membrane were indeed shown to affect stability and size of LD in the cytoplasm. For example, phosphatidylethanolamine (PE) was found to destabilize the LD membrane and thereby induce LD fusion, resulting in larger LD (Thiam et al., 2013). Phosphatidylcholine (PC), on the other hand, has been suggested to stabilize the LD surface and hence inhibit fusion, resulting in smaller droplets in Drosophila (Guo et al., 2008). Whether these mechanisms are also involved in the modulation of lipid droplet size in the mammary epithelial cells has yet to be determined.

The abundance of these proteins and lipids within the mammary epithelial cell may influence the size of the MFG. Therefore, a detailed proteome and lipidome analysis of different sized MFG fractions may reveal which cellular components play a role in size regulation of the MFG during the synthesis and secretion process. Hence, MFG of individual cows were separated accord- ing to their size, resulting in a fraction of small MFG and a fraction of large MFG. The protein and lipid composition of both fractions was analyzed by mass spectrometry-based proteomics for protein composition, and HPLC-evaporating light scattering detector (ELSD) and GC for lipid composition. The comprehensive analysis of proteins and lipids in different MFG size fractions may provide targets for further studies aimed at understanding what determines MFG size.

\section{MATERIALS AND METHODS}

\section{Milk Samples}

Milk samples were collected from 7 healthy Holstein cows in mid lactation (100-200 d) between December 2011 and January 2012 from the Wageningen University Farm (Wageningen, the Netherlands). Raw milk samples were obtained immediately after milking in the morning and transported to the laboratory for subsequent analyses on the same day. Milk composition was analyzed using a MilkoScan 134A/B (Foss Electric, Hillerød, Denmark).

\section{Milk Fat Globule Separation}

Milk samples were heated to $40^{\circ} \mathrm{C}$ in a water bath. The heated milk samples were then centrifuged at 190 $\times g$ for $10 \mathrm{~min}$ at $15^{\circ} \mathrm{C}$ to separate cream and skim milk. The top layer of cream was subsequently removed for centrifugation with PBS ( $\mathrm{pH} 6.8,0.1 M, 1: 10$, vol:vol) at $390 \times g$ for $10 \mathrm{~min}$ at $10^{\circ} \mathrm{C}$. The washing solution was discarded after centrifugation. This step was repeated 3 times. The cream obtained using this procedure was the large MFG fraction. The skim milk was centrifuged at $390 \times g$ for $10 \mathrm{~min}$ at $10^{\circ} \mathrm{C}$. This step was repeated 3 times. The cream after each centrifugation step was discarded except after the last step. The obtained cream was washed 3 times with PBS ( $\mathrm{pH} 6.8$, $0.1 M, 1: 10$, vol:vol) at $390 \times g$ for $10 \mathrm{~min}$ at $10^{\circ} \mathrm{C}$. The cream obtained using this procedure was the small MFG fraction.

\section{Determination of Globule Diameters}

The small and large MFG fractions were diluted with $35 \mathrm{~m} M$ EDTA/NaOH buffer (pH 7.0, 1:1, vol:vol) to dissociate casein micelles, followed by heating to $40^{\circ} \mathrm{C}$. The globule diameters were analyzed using a Mastersizer 2000 (Malvern Instrument Ltd., Malvern, UK). The refractive index of the cream samples was 1.458 at $633 \mathrm{~nm}$. Milli-Q water was used as a dispersant, and its refractive index was 1.33 . 


\section{Separation of Proteins from Milk Fat Globules}

A $0.4 \%$ SDS solution was added to the small and large MFG fractions (1:1, vol:vol). After cooling at $4^{\circ} \mathrm{C}$ for $15 \mathrm{~min}$, the cream solution was sonicated for 3 min (Transsonic 700, Singen, Germany). It was then centrifuged at $1,500 \times g$ for $5 \mathrm{~min}$ at $10^{\circ} \mathrm{C}$. The bottom part of the solution contains the proteins. Because serum proteins have been washed away during the initial MFG separation, this protein fraction is assumed to represent the MFGM proteins. Protein concentration was determined using BCA assay (Thermo Scientific Pierce BCA protein assay kit, Waltham, MA).

\section{Proteomics Analysis by Filter-Aided Sample Preparation-Dimethyl Labeling-nanoLC- Orbitrap-Tandem MS}

The MFGM proteins $(10 \mu \mathrm{g})$ of the large and small MFG fraction were prepared and compared by using filter-aided sample preparation (FASP)-dimethyl labeling-nanoLC-Orbitrap-MS/MS. The procedure as described below was identical to that from $\mathrm{Lu}$ et al. (2011).

Filter-Aided Sample Preparation. The protein clean up and digestion method used was based on FASP with some modifications. Our procedure was as follows: protein samples were diluted in the SDT-lysis buffer $(100 \mathrm{~m} M$ Tris $/ \mathrm{HCl} \mathrm{pH} 8.0+4 \%$ SDS $+0.1 M$ dithiothreitol) to get a $1 \mu \mathrm{g} / \mu \mathrm{L}$ protein solution. The samples were then incubated at $95^{\circ} \mathrm{C}$ for $5 \mathrm{~min}$ and cooled down to room temperature. Ten microliters of each sample was directly added to a Pall $3 \mathrm{~K}$ omega filter and centrifuged at $20,000 \times g$ for $1 \mathrm{~min}$ at room temperature. Then, $100 \mu \mathrm{L}$ of UT $(100 \mathrm{~m} M$ Tris/HCl $\mathrm{pH} 8.0+8 M$ urea) was added to the filter and centrifuged at $20,000 \times g$ for $30 \mathrm{~min}$. Next, $100 \mu \mathrm{L}$ of IAA (0.05 $M$ iodoacetamide in UT) was added and mixed, followed by $10 \mathrm{~min}$ of incubation at room temperature and centrifugation at $20,000 \times g$ for $30 \mathrm{~min}$. Subsequently, $110 \mu \mathrm{L}$ of UT was added to the filter after which it was centrifuged at $20,000 \times g$ for $30 \mathrm{~min}$ at room temperature. This step was repeated 2 times with 120 and $130 \mu \mathrm{L}$ of UT, respectively. Then, $140 \mu \mathrm{L}$ of $0.05 \mathrm{M} \mathrm{NH}_{4} \mathrm{HCO}_{3}$ (ABC) was added to the filter unit, after which it was centrifuged at 20,000 $\times g$ for $30 \mathrm{~min}$ at room temperature. Finally, $100 \mu \mathrm{L}$ of ABC containing $0.5 \mu \mathrm{g}$ of trypsin was added, followed by overnight incubation at room temperature. Finally, the filter unit was centrifuged at $20,000 \times g$ for $30 \mathrm{~min}$. The sample obtained was acidified with $10 \%$ trifluoroacetic acid to adjust the $\mathrm{pH}$ of the sample to 2 to 4 . These samples were ready for either direct nanoLC-LTQ-Orbitraptandem MS (MS/MS) analysis or dimethyl labeling.
Dimethyl Labeling. The peptide samples prepared with FASP were labeled as described before (Boersema et al., 2009). C18+ Stage tip columns were made in house. The C18+ Stage tip column was washed 3 times with $200 \mu \mathrm{L}$ of methanol. It was then conditioned with $100 \mu \mathrm{L}$ of $1 \mathrm{~mL} / \mathrm{L}$ of $\mathrm{HCOOH}$. The peptide samples were loaded on the C18+ Stage tip column followed by washing with $100 \mu \mathrm{L}$ of $1 \mathrm{~mL} / \mathrm{L}$ of $\mathrm{HCOOH}$. The column was then slowly flushed with $100 \mu \mathrm{L}$ of the labeling reagent (light: $\mathrm{CH}_{2} \mathrm{O}$ or heavy: $\mathrm{CD}_{2} \mathrm{O}$ ) in about 10 min. The column was washed with $200 \mu \mathrm{L}$ of $1 \mathrm{~mL} / \mathrm{L}$ of $\mathrm{HCOOH}$. The labeled peptides were eluted with $50 \mu \mathrm{L}$ of $70 \%$ acetonitrile/30\% $1 \mathrm{~mL} / \mathrm{L}$ of $\mathrm{HCOOH}$ from the columns. Two samples, one with light dimethyl label and one heavy dimethyl label, were then mixed, after which the volume was adjusted to exactly $100 \mu \mathrm{L}$ by adding $1 \mathrm{~mL} / \mathrm{L}$ of $\mathrm{HCOOH}$. These samples were ready for analysis by nanoLC-LTQ-Orbitrap-MS/MS.

NanoLC-LTQ-Orbitrap-MS/MS. The samples were analyzed by injecting $18 \mu \mathrm{L}$ of sample (Proxeon $\mathrm{nLC}$ ) over a $0.10 \times 32 \mathrm{~mm}$ Prontosil $300-5-\mathrm{C} 18 \mathrm{H}$ (Bischoff, Germany) pre-concentration column (prepared in house) at a maximum pressure of 270 bar. Peptides were eluted from the pre-concentration column onto a $0.10 \times 200 \mathrm{~mm}$ Prontosil $300-3-\mathrm{C} 18 \mathrm{H}$ analytical column with an acetonitrile gradient at a flow rate of $0.5 \mu \mathrm{L} / \mathrm{min}$. The gradient consisted of an increase from 9 to $34 \%$ acetonitrile in water with $1 \mathrm{~mL} / \mathrm{L}$ of $\mathrm{HCOOH}$ in 200 min followed by a fast increase in the percentage acetonitrile to $80 \%$ (with $20 \%$ water and $1 \mathrm{~mL} / \mathrm{L}$ of $\mathrm{HCOOH}$ in both the acetonitrile and the water) in 3 min as a column cleaning step.

Between the pre-concentration and analytical column, an electrospray potential of $3.5 \mathrm{kV}$ was applied directly to the eluent via a solid 0.5 - $\mathrm{mm}$ platinum electrode fitted into a P777 Upchurch microcross. Full scan positive mode FTMS spectra were obtained between $\mathrm{m} / \mathrm{z} 380$ and 1,400 on a LTQ-Orbitrap XL (Thermo Electron, San Jose, CA). The MS/MS scans of the 10 most abundant doubly and triply charged peaks in the FTMS scan were recorded in data dependent mode in the linear trap (MS/MS threshold $=5,000,60$ s exclusion duration).

Identification and Quantification of Proteins. In total, 7 LC-MS/MS raw files were generated (the large vs. small MFG fractions of milk samples from 7 cows). Each run with all MS/MS spectra obtained was analyzed using MaxQuant 1.2.2.5 with Andromeda as the peptide search engine (Cox and Mann, 2008; Cox et al., 2011). The database for peptide/protein searches was a concatenated bovine reference database downloaded from Uniprot (www.uniprot.org, 25-10-15) with reverse sequences generated by MaxQuant. The contaminants database of MaxQuant was also used for 
peptide/protein searches, which includes sequences of trypsin and human keratins. Identification and quantification of proteins was simultaneously performed by MaxQuant. Carbamidomethylation of cysteines was set as a fixed modification and oxidation of methionine, N-terminal acetylation, and deamidation of asparagine or glutamine were set as variable modifications for both identification and quantification. Peptide tolerance was set at $10 \mathrm{ppm}$, and fragment ions tolerance at $0.5 \mathrm{amu}$. Mass deviation of 0.5 Da was set as the maximum allowed for MS/MS peaks, and a maximum of 2 missed cleavages were allowed. Maximum false discovery rates were set to $1 \%$, both on the peptide and protein level. Minimum required peptide length was 6 AA for both identification and quantification. A minimum of 2 peptides for each protein was required for identification. Dimethyl labeling was based on doublets with dimethLys0 and dimethNter0 as light, and dimethLys4 and dimethNter4 as heavy. Only razor and unique peptides were used for quantification. For each LC-MS run, MaxQuant calculated normalized peptide ratios so that the median of their logarithms was zero, which corrects for unequal protein loading, assuming that the majority of proteins show no differential regulation, as described by Cox and Mann (2008). The median H/L normalized ratio for each protein was used, and the average $\mathrm{H} / \mathrm{L}$ normalized ratios of 7 biological replicates were used for statistical analysis.

\section{Proteomics Data Analysis and GO Enrichment Analysis}

One sample $t$-tests were performed on the protein ratio of each protein in 7 comparisons (large MFG/ small MFG fraction), comparing the average $\log _{2}$ ratio to 0 . The Gene Ontology (GO) enrichment analysis of significantly changed proteins $(P<0.05)$ was done using DAVID bioinformatics Resources 6.7 (http:// david.abcc.ncifcrf.gov/; Huang et al., 2009). The GO terms shown in the Results section were significantly enriched compared with the GO terms of all proteins identified in this study. Significance was defined as $P$ $<0.05$ where the Fisher Exact test was adopted to measure the gene enrichment in GO terms.

\section{Lipid Extraction}

For lipid extraction, analytical reagent-grade methanol and chloroform were purchased from Bio-Lab Ltd. Laboratories (Jerusalem, Israel). For HPLC analysis, dichloromethane, methanol, and ethanol, HPLC-grade and analytical reagent-grade, were purchased from Bio-Lab. The Tg standard triolein (>99\% pure) was purchased from Supelco (Bellefonte, PA). Cholesterol
(>99\% pure) and phospholipid standards were supplied by Sigma-Aldrich Israel Ltd. (Rehovot, Israel), and consisted of PE (1,2-dioleoyl-sn-glycero-3-phosphoethanolamine, purity 99\%), phosphatidylinositol (PI; L- $\alpha$ phosphatidylinositol ammonium salt, from bovine liver, purity 98\%), phosphatidylserine (PS; 1,2-dioleoyl-snglycerol-3-phospho-L-serine sodium salt, purity 95\%), phosphatidylcholine (PC; 1,2-dioleoyl-sn-glycero3-phosphocholine, purity 99\%), and sphingomyelin (SM; from bovine brain, purity 97\%). As an internal standard for free fatty acids, C11:0 (undecanoic acid, purity 99\%) from Sigma-Aldrich was used.

A protocol adapted from the cold extraction procedure developed previously (Folch et al., 1957) was used for the extraction of total lipids from the milk. Total lipids were extracted from samples containing approximately $200 \mathrm{mg}$ of cream using chloroform-methanol $(2: 1, \mathrm{vol} / \mathrm{vol})$ as described previously (Mesilati-Stahy et al., 2012). For the HPLC analysis, $100 \mu \mathrm{L}$ of chloroform-ethanol $(97: 3 \mathrm{vol} / \mathrm{vol})$ was added to the evaporated tubes containing lipids and stored at $-20^{\circ} \mathrm{C}$ until injection into the HPLC.

\section{Phospholipid and Cholesterol Analysis}

Quantification of PL and $\mathrm{Tg}$, and determination of lipid class, were performed by HPLC (HP 1200, Agilent Technologies, Santa Clara, CA) combined with an evaporative light-scattering detector (ELSD1200, Agilent Technologies). The separation process was managed by ChemStation software (Agilent Technologies), which permitted the acquisition of data from the ELSD, with an injection volume of $10 \mu \mathrm{L}$. The separation was conducted as described previously (Argov-Argaman et al., 2012) using normal-phase chromatography on a silica column (Zorbax, Agilent Technologies). Calibration, and lipid concentration and composition, were determined using external standards (Sigma-Aldrich).

The PL were identified and quantified by normalphase liquid chromatography (HP 1200, Agilent Technologies) combined with an ELSD (1200 series ELSD, Agilent Technologies). The method employed for lipid separation, which uses dichloromethane, methanol, and double-distilled water, was as previously described (Mesilati-Stahy et al., 2011). Briefly, a column (Zorbax RX-SIL, $4.6 \times 250 \mathrm{~mm}$, Agilent Technologies) was heated to $50^{\circ} \mathrm{C}$, and flow was set to $1 \mathrm{~mL} / \mathrm{min}$. The ELSD was heated to $65^{\circ} \mathrm{C}$, nitrogen pressure was 3.9 bar, a no. 5 filter was used, and gain (sensitivity) was set to 7 for the first $11 \mathrm{~min}$ and then changed to 9 until the end of the run to enable detection of lower-abundance lipid components. Injection volume was $20 \mu \mathrm{L}$. This allowed separation of triacylglycerol, 2 isomers of diacylglycerol, monoacylglycerol, cholesterol, 
Table 1. Size parameters of fat globules in whole milk, the small milk fat globule (SMFG), and the large milk fat globule (LMFG) fraction, and milk composition of the whole milk ${ }^{1}$

\begin{tabular}{|c|c|c|c|c|c|c|c|}
\hline Fraction & $\mathrm{d}_{43}, \mu \mathrm{m}$ & $\mathrm{d}_{32}, \mu \mathrm{m}$ & $\begin{array}{c}\text { Specific } \\
\text { surface area, } \\
\mathrm{m}^{2} / \mathrm{g} \text { of fat }\end{array}$ & $\begin{array}{c}\text { Protein content } \\
\text { per unit area, } \\
\mathrm{mg} / \mathrm{m}^{2}\end{array}$ & Fat, $\%$ & Protein, \% & Lactose, $\%$ \\
\hline $\begin{array}{l}\text { Whole milk } \\
\text { SMFG } \\
\text { LMFG }\end{array}$ & $\begin{array}{l}3.95 \pm 0.26^{\mathrm{a}} \\
3.32 \pm 1.21^{\mathrm{b}} \\
7.61 \pm 0.90^{\mathrm{c}}\end{array}$ & $\begin{array}{l}3.47 \pm 0.27^{\mathrm{a}} \\
2.93 \pm 1.06^{\mathrm{b}} \\
4.31 \pm 0.17^{\mathrm{c}}\end{array}$ & $\begin{array}{l}1.89 \pm 0.15^{\mathrm{a}} \\
2.23 \pm 0.81^{\mathrm{b}} \\
1.16 \pm 0.05^{\mathrm{c}}\end{array}$ & $\begin{array}{l}3.56 \pm 0.45^{\mathrm{a}} \\
3.38 \pm 0.89^{\mathrm{a}} \\
4.06 \pm 0.20^{\mathrm{a}}\end{array}$ & $3.95 \pm 0.56$ & $3.58 \pm 0.23$ & $4.53 \pm 0.07$ \\
\hline
\end{tabular}

${ }^{a-c}$ Denotes significant differences when paired sample Student $t$-test was applied $(P<0.01)$.

${ }^{1}$ Diameters $\mathrm{d}_{43}=\sum n_{i} d_{i}^{4} / \sum n_{i} d_{i}^{3}, \mathrm{~d}_{32}=\sum n_{i} d_{i}^{3} / \sum n_{i} d_{i}^{2}$, where $n_{i}$ is the number of fat globules with diameter $d_{i}$; specific surface area $=6 /\left(\mathrm{d}_{32} \times\right.$ $\varphi$ ) assuming $\varphi=0.92 \mathrm{~g} / \mathrm{L}$ for fat globule (Walstra et al., 2005). Data values represents mean $\pm \mathrm{SD}$ of milk samples and separated MFG fractions from seven cows

free fatty acids, PE, PI, PS, PC, and SM. Quantification was based on areas under the standard curve of each lipid standard. The power equations were $\mathrm{Tg}, \mathrm{y}=$ $0.0014 \mathrm{x}^{0.8695}\left(\mathrm{R}^{2}=0.995\right)$; cholesterol, $\mathrm{y}=0.0245 \mathrm{x}^{0.581}$ $\left(\mathrm{R}^{2}=0.9925\right) ; \mathrm{PE}, \mathrm{y}=0.1369 \mathrm{x}^{0.437}\left(\mathrm{R}^{2}=0.9908\right) ; \mathrm{PI}$, $\mathrm{y}=0.0103 \mathrm{x}^{0.7918}\left(\mathrm{R}^{2}=0.9898\right) ; \mathrm{PS}=1.73 \mathrm{X}^{0.41}\left(\mathrm{R}^{2}=\right.$ 0.99); PC, y $=0.0408 \mathrm{x}^{0.5077}\left(\mathrm{R}^{2}=0.9986\right)$; and SM, y $=0.0667 \mathrm{x}^{0.5287}\left(\mathrm{R}^{2}=0.9981\right)$. The weight of each of the polar lipids in $1 \mathrm{~mL}$ of milk was calculated according to the power equations, and its weight percentage of total membrane lipids $(\mathrm{PE}+\mathrm{PI}+\mathrm{PC}+\mathrm{SM}+$ cholesterol $)$ was determined.

\section{Fatty Acid Composition}

Milk-fat composition was measured at the Qlip laboratory (Zutphen, the Netherlands). Milk fat was extracted from the milk samples, and FAME were prepared from fat fractions as described in ISO Standard 15884 (ISO-IDF, 2002a). Methyl esters were analyzed according to ISO Standard 15885 (ISO-IDF, 2002b) on a Trace GC Ultra chromatograph (Thermo Electron Corporation), using a Varian Fame Select column (100 $\mathrm{m} \times 0.25 \mathrm{~mm}$ ID; Varian Inc., Palo Alto, CA). The initial temperature was held at $70^{\circ} \mathrm{C}$ for $1 \mathrm{~min}$, raised to $225^{\circ} \mathrm{C}$ at $3^{\circ} \mathrm{C} / \mathrm{min}$, and held at $225^{\circ} \mathrm{C}$ for $5 \mathrm{~min}$. A volume of $1 \mu \mathrm{L}$ was injected. Each peak was identified and quantified using pure methyl esters (Sigma-Aldrich, Zwijndrecht, the Netherlands; Larodan, Malmö, Sweden). The fatty acids were expressed as a proportion of total fat weight.

\section{RESULTS}

\section{Fat Globule Size Distribution}

Two fractions containing MFG with an average diameter of $3.3 \pm 1.2 \mu \mathrm{m}$ and $7.6 \pm 0.9 \mu \mathrm{m}$, were separated from milk samples of 7 individual cows (Table 1). As expected, the small MFG fraction had a larger specific membrane surface area than the large MFG fraction (Table 1).

\section{Fatty Acid Composition of Different Sized MFG}

The fatty acid composition of the 2 MFG size fractions was determined by GC. Table 2 gives an overview of the significantly changed fatty acids between the 2 different globule sizes. This table shows that the significant differences were in unsaturated, medium, and long-chain fatty acids. Of the SFA, only the long-chain C17:0, C18:0, and C20:0 differed significantly.

The total amount of saturated and unsaturated fatty acids and CLA were compared (Table 3). This table shows that the amount of SFA was significantly higher in the large MFG fraction, whereas that of UFA (total UFA, total MUFA, and CLA) was higher in the small MFG fraction.

\section{Phospholipid Composition in Different Sized MFG}

The phospholipid composition of the different sized MFG fractions was determined using HPLC-ELSD (Table 4). A significant difference was found in the

Table 2. Significant different fatty acids ( $\mathrm{g} / 100 \mathrm{~g}$ of fat) in the large and small milk fat globule (MFG) fractions ${ }^{1}$

\begin{tabular}{lcccccccccc}
\hline $\begin{array}{l}\text { Fatty acid, } \\
\text { g/100 g of fat }\end{array}$ & C-10:1 & C-12:1 & $\begin{array}{c}\text { C-14:1 } \\
\text { cis-9 }\end{array}$ & C-17:0 & C-18:0 & $\begin{array}{c}\text { C-18:1 } \\
\text { trans-10 }\end{array}$ & $\begin{array}{c}\text { C-18:1 } \\
\text { cis-9 }\end{array}$ & $\begin{array}{c}\text { C-18:3 } \\
\text { cis-9,12,15 }\end{array}$ & $\begin{array}{c}\text { C-18:2 cis-9, } \\
\text { trans-11 (CLA) }\end{array}$ & C-20:0 \\
\hline Small MFG & $\mathbf{0 . 3 4 8}$ & $\mathbf{0 . 1 2 3}$ & $\mathbf{1 . 3 2 4}$ & 0.474 & 8.879 & 0.190 & $\mathbf{1 7 . 5 3 0}$ & $\mathbf{0 . 3 9 6}$ & $\mathbf{0 . 3 8 3}$ \\
Large MFG & 0.324 & 0.112 & 1.232 & $\mathbf{0 . 4 8 3}$ & $\mathbf{9 . 4 6 3}$ & $\mathbf{0 . 1 9 5}$ & 17.071 & 0.386 & 0.120 \\
\hline
\end{tabular}

${ }^{1}$ Significant increases are shown in bold. 
Table 3. Total amount of fatty acids and cholesterol ( $\mathrm{g} / 100 \mathrm{~g}$ of fat), by type, in the large and small milk fat globule (MFG) fractions ${ }^{1}$

\begin{tabular}{lcccc}
\hline $\begin{array}{l}\text { Fatty acid, } \mathrm{g} / 100 \mathrm{~g} \\
\text { of fat }\end{array}$ & Cholesterol & Total SFA & Total UFA & CLA \\
\hline Small MFG & $\mathbf{0 . 2 9 4}$ & 71.691 & $\mathbf{2 8 . 3 0 9}$ & $\mathbf{0 . 3 8 3}$ \\
Large MFG & 0.217 & $\mathbf{7 2 . 4 5 2}$ & 27.548 & 0.358 \\
\hline
\end{tabular}

${ }^{1}$ Significant increases are shown in bold.

content of PI and PE. No difference was observed in the other 3 phospholipids.

\section{Protein Composition of Different Sized MFG}

In total, 4,688 peptides were identified and quantified, resulting in 156 proteins identified and quantified that were used for further statistical analysis. Forty-nine and 23 proteins were significantly higher in concentration in the large and small MFG fractions, respectively (Tables 5 and 6). Next, a functional analysis of significantly changed proteins was performed based on GO. In the large MFG fraction, these proteins were mainly associated with protein transport/stabilization, host defense, and cytoskeleton organization. These proteins showed enrichment in the subcellular locations "cytoplasmic vesicle" and "intracellular non-membrane-bounded organelle," which was mainly cytoskeleton/chromosome (Figures 1 and 3). Proteins significantly enriched in the small MFG fraction were mainly associated with lipid metabolic processes and cholesterol synthesis and showed "apical membrane" and "integral to membrane" as enriched subcellular location (Figures 2 and 3). Not only the low abundant proteins, but also the major proteins differed between the large and small MFG fractions, with an increase of lactadherin (Q95114, MFGE8), perifilin-2 (Q9TUM6, ADFP), and glycosylation-dependent cell adhesion molecule 1 (P80195, GLYCAM1/PP3) in the large MFG fraction and an increase of platelet glycoprotein 4 (P26201, CD36) and mucins (Q8WML4, MUC1; Q8MI01, MUC15; and F1MRA6, MUC16) in the small MFG fraction. The most significant difference between the large and small MFG fractions was in the host defense proteins.
Cathelicidins (P22226, CATHL1, P54228, CATHL6, and P33046, CATHL4), lactoferrin (P24627, LTF), complement C3 (Q2UVX4, C3), lymphocyte cytosolic protein 1 (Q3ZC00, LCP1), and monocyte differentiation antigen CD14 (Q95122, CD14) were more abundant in the large MFG fraction. There was also a different distribution of lipid synthesis enzymes between the MFG fractions. Fatty acid synthase (Q71SP7, FASN) was enriched in the large MFG fraction, while acyl-CoA synthetase (Q1LZF6, F1MEX9, ACSL), lanosterol synthase (P84466, LSS), acetyl-CoA carboxylase 1 (Q9TTS3, ACACA), sterol-4- $\alpha$-carboxylate 3-dehydrogenase (decarboxylating; Q3ZBE9, NSDHL), and glycerol-3-phosphate acyltransferase 4 (A3FPG8, AGPAT6) were enriched in the small MFG fraction.

\section{DISCUSSION}

Unlike factors that may influence the size of intracellular LD in other cell types, factors determining the size of secreted MFG have not been extensively studied. Due to the contribution of MFGM proteins and lipids in MFG synthesis and secretion, we performed a comprehensive compositional analysis of different sized MFG fractions to find proteins and lipids that may influence MFG size and thereby provide targets for further studies in this area.

The fatty acid composition as reported in Tables 2 and 3 showed that the large MFG fraction was characterized by a lower concentration of UFA and a higher concentration of stearic acid compared with the small MFG fraction. This is in agreement with previous literature on the difference in fatty acid composition between large and small MFG (Timmen and Patton,

Table 4. Phospholipid composition (weight \% of total phospholipids) in the large and small milk fat globule (MFG) fraction 1

\begin{tabular}{lccccc}
\hline Phospholipid weight, $\%$ & PI* & PE* & PS & PC & SM \\
\hline Small MFG & 4.79 & 27.46 & 7.77 & 37.18 & 22.80 \\
Large MFG & 10.30 & 19.50 & 8.04 & 36.46 & 25.71 \\
\hline${ }^{1}$ PI = phosphatidylinositol; PE = phosphatidylethanolamine; PS = phosphatidylserine; PC = phosphatidyl- \\
choline; SM = sphingomyelin. \\
*Significant at $P<0.05$.
\end{tabular}


Table 5. Proteins with significantly higher concentration in the large milk fat globules (MFG) fraction and their average $\log _{2}$ protein ratio (large/small) in the 7 individual cows ${ }^{1}$

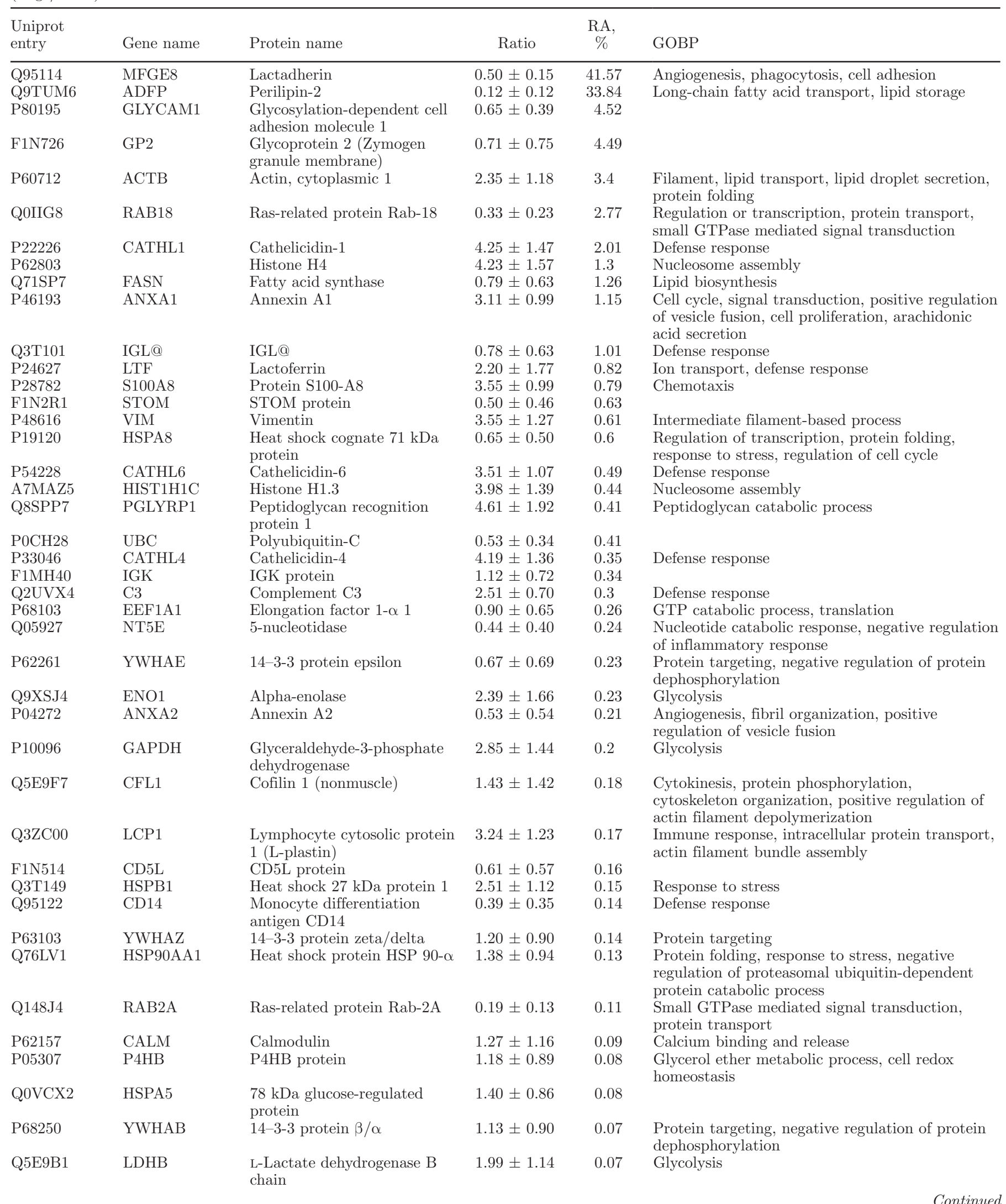


Table 5 (Continued). Proteins with significantly higher concentration in the large milk fat globules (MFG) fraction and their average log 2 protein ratio (large/small) in the 7 individual cows ${ }^{1}$

\begin{tabular}{|c|c|c|c|c|c|}
\hline $\begin{array}{l}\text { Uniprot } \\
\text { entry }\end{array}$ & Gene name & Protein name & Ratio & $\underset{\%}{\mathrm{RA}}$ & GOBP \\
\hline A1L528 & RAB1A & Ras-related protein Rab-1A & $0.27 \pm 0.29$ & 0.06 & $\begin{array}{l}\text { Small GTPase mediated signal transduction, } \\
\text { protein transport }\end{array}$ \\
\hline Q27965 & HSPA1B & Heat shock $70 \mathrm{kDa}$ protein $1 \mathrm{~B}$ & $0.83 \pm 0.52$ & 0.06 & DNA repair, response to stress, anti-apoptosis \\
\hline P19803 & ARHGDIA & $\begin{array}{l}\text { Rho GDP-dissociation } \\
\text { inhibitor } 1\end{array}$ & $0.65 \pm 0.48$ & 0.05 & $\begin{array}{l}\text { Rho protein signal transduction, positive } \\
\text { regulation of GTPase activity }\end{array}$ \\
\hline P49951 & CLTC & Clathrin heavy chain 1 & $1.74 \pm 0.85$ & 0.05 & Vesicle mediated transport/protein transport \\
\hline P19483 & ATP5A1 & ATP synthase subunit $\alpha$ & $2.08 \pm 0.85$ & 0.04 & $\begin{array}{l}\text { Cell proliferation, ATP metabolic and proton } \\
\text { transport, lipid metabolic process }\end{array}$ \\
\hline Q863B3 & SND1 & $\begin{array}{l}\text { Staphylococcal nuclease } \\
\text { domain-containing protein } 1\end{array}$ & $0.55 \pm 0.44$ & 0.02 & Regulation of transcription \\
\hline
\end{tabular}

${ }^{1}$ Proteins were listed in order of descending protein intensity. Ratio is presented as average \pm SD. RA $=$ relative abundance (relative to butyrophilin as \%). GOBP = Gene Ontology biological process.

Table 6. Proteins with significantly higher concentration in the small milk fat globules (MFG) fraction and their average $\log _{2} \operatorname{protein}$ ratio (large/small) in the 7 individual cows ${ }^{1}$

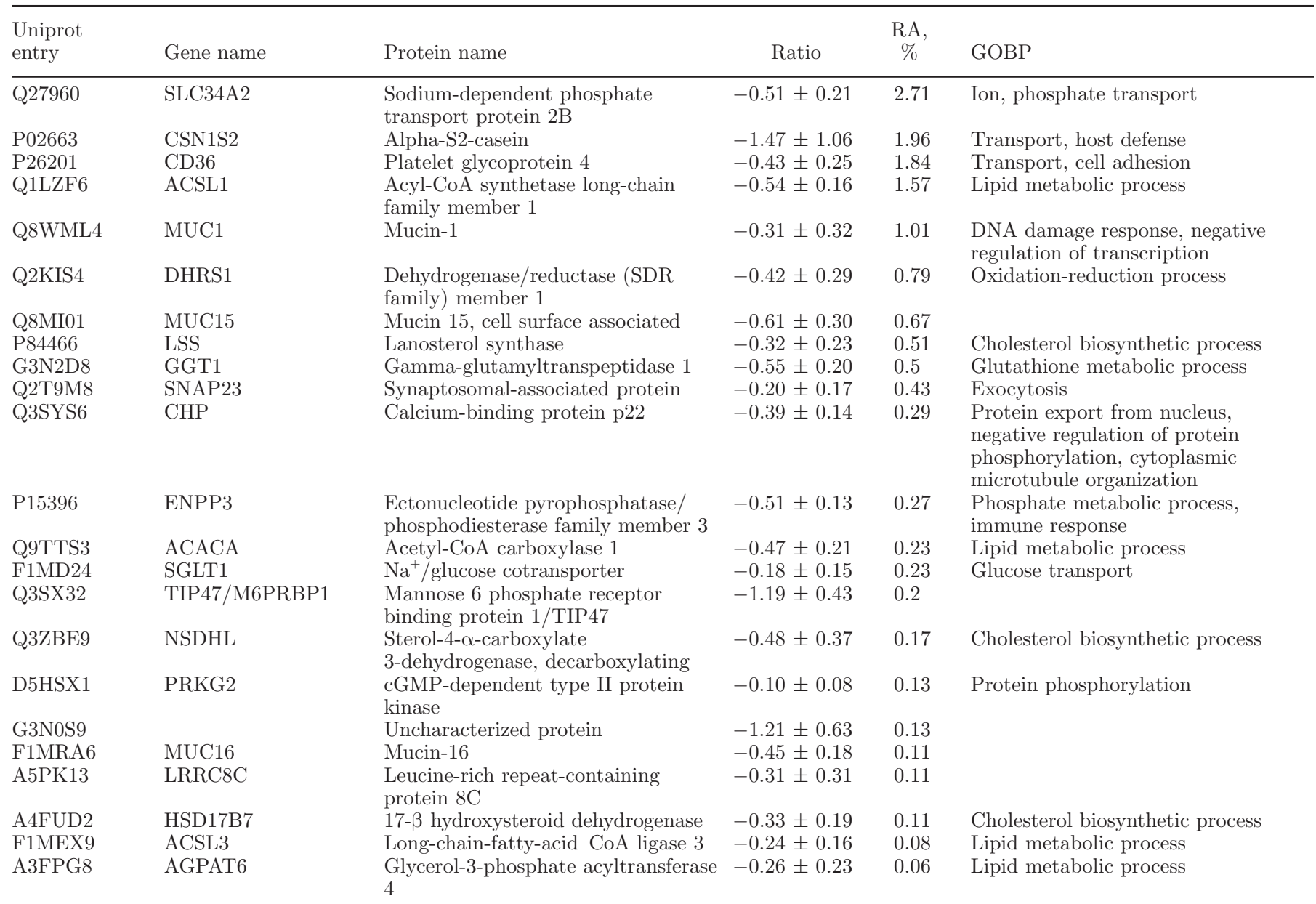

${ }^{1}$ Proteins were listed in order of descending protein intensity. Ratio is presented as average \pm SD. RA = relative abundance (relative to butyrophilin as \%). GOBP = Gene Ontology biological process. 


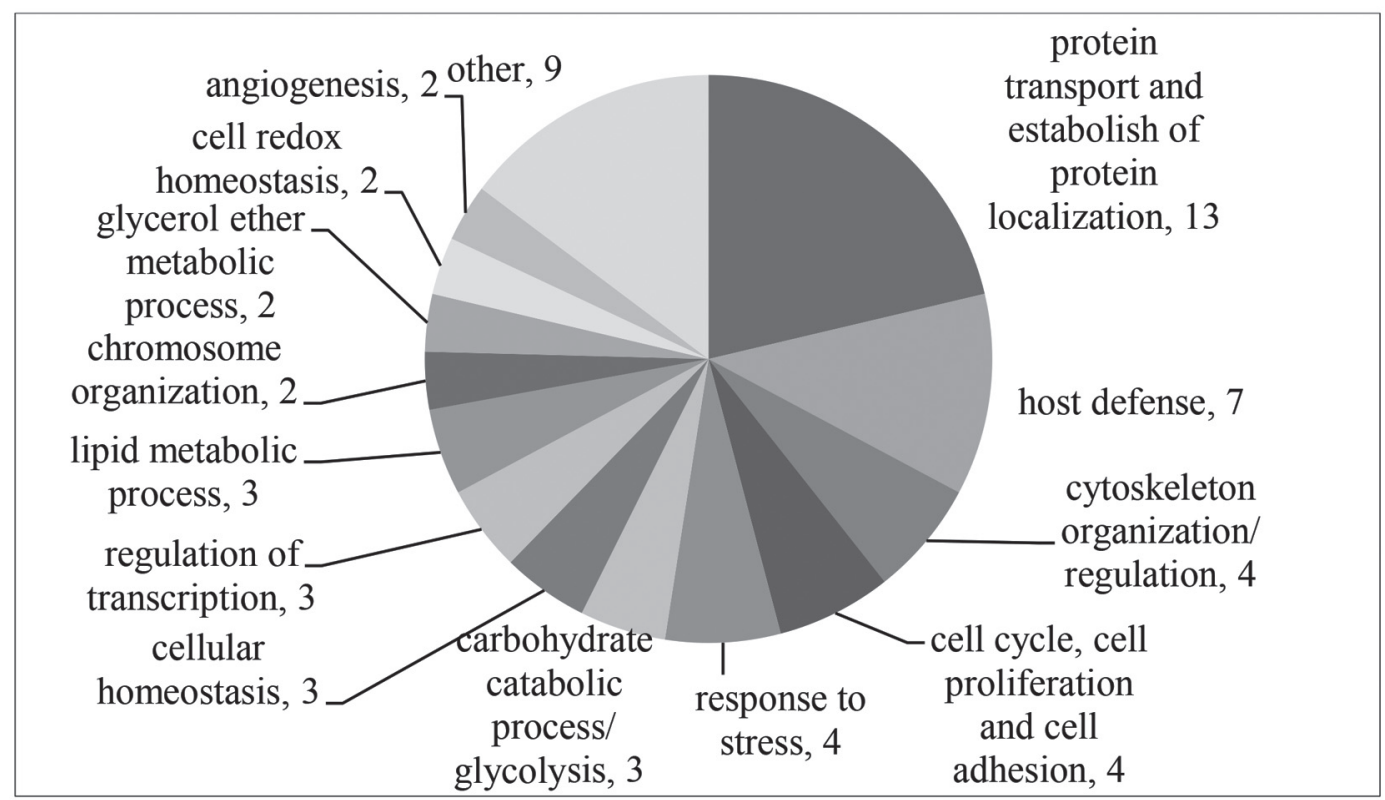

Figure 1. Biological functions of proteins with significantly higher concentration in the large MFG fraction compared with the small MFG fraction. Functions were assigned based on gene ontology as well as literature references for each protein. The number of proteins in each function category is labeled in the chart.

1988; Briard et al., 2003). It has been hypothesized that this difference in lipid composition might be related to ease of fusion of droplets with different fatty acid composition (Timmen and Patton, 1988). An alternative cause of this difference might be the increased amount of MFGM material, with the small MFG fraction having twice the amount of membrane as the large MFG fraction (Table 1). As MFGM is relatively rich in UFA
(Jensen and Nielsen, 1996), the higher amount of UFA in the small MFG fraction may be related to this relative increase in membrane. Briard et al. (2003) have calculated that there should be up to $1 \%$ more oleic acid (C18:1 cis-9) in small MFG than in large MFG, if the compositional differences between globule sizes would be due to their MFGM content only. This may therefore explain the increased UFA content, oleic acid

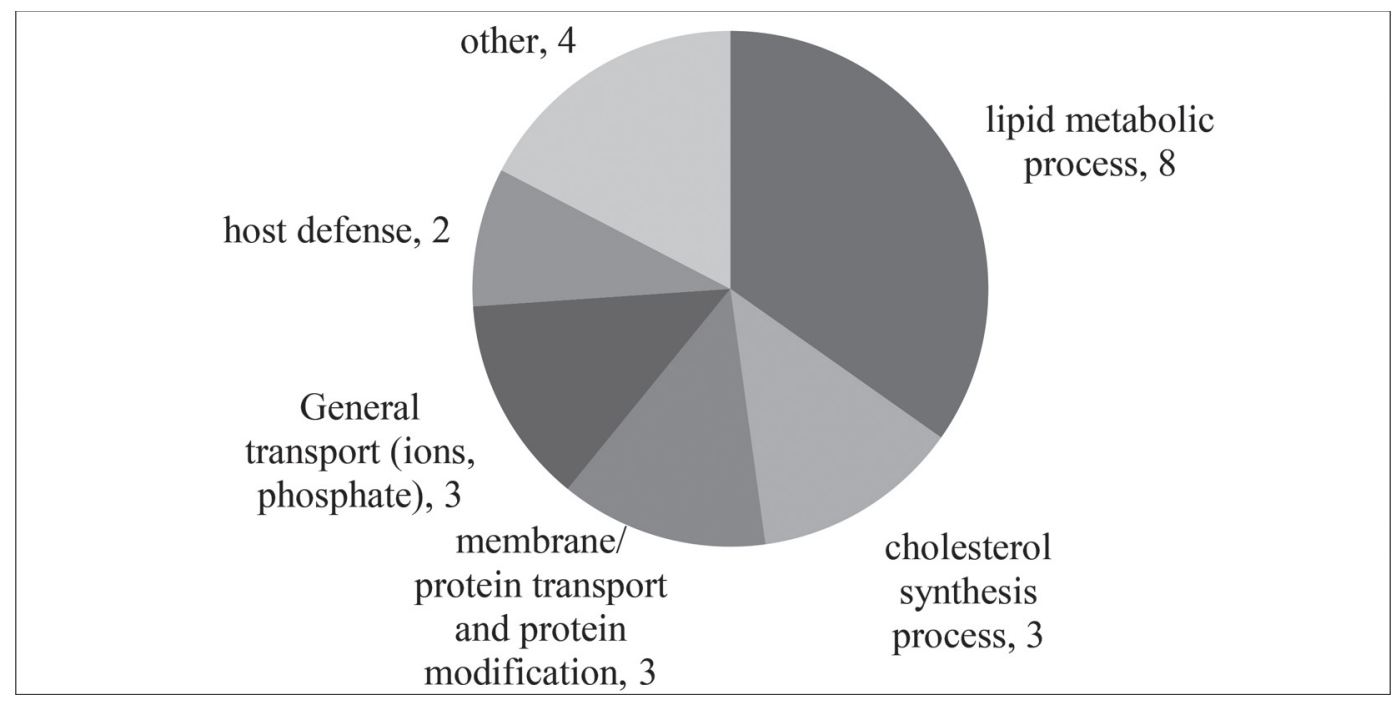

Figure 2. Biological functions of proteins with significantly higher concentration in the small MFG fraction compared with the large MFG fraction. Functions were assigned based on gene ontology as well as literatures references for each protein. The number of proteins in each function category is labeled in the chart. 


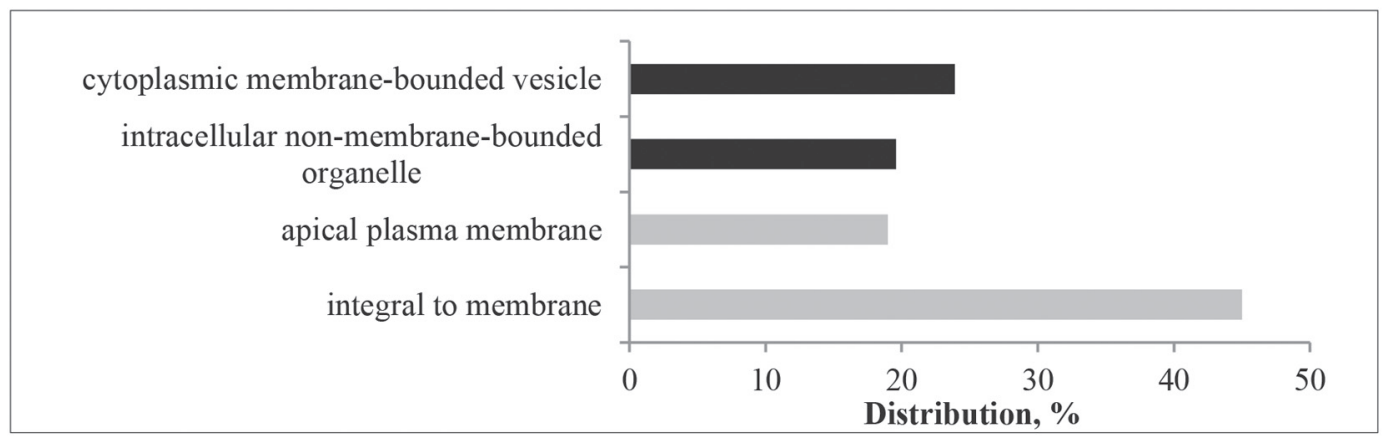

Figure 3. Gene ontology (cellular component) enrichment of significantly changed proteins in the large and small MFG fractions by using DAVID Bioinformatics Resources 6.7. The GO terms shown in this figure were significantly enriched $(P<0.05)$ compared with the GO of all proteins identified in this study. Black = GO term enriched in the large MFG fraction. Grey = GO term enriched in the small MFG fraction.

content specifically, in the small MFG fraction (Tables 2 and 3$)$.

Of the phospholipids, PE is significantly different (Table 4). The concentration of PE in the membrane is significantly lower in the large MFG compared with the small MFG fraction. Although the function of this polar lipid within mammary gland epithelial cells is not well understood, the function of PE has been implied in other biological systems, as described in the Introduction. The PE was previously found to destabilize the LD membrane, resulting in LD fusion and an increase in size (Thiam et al., 2013). This may thereby explain the lower concentration of PE in the large MFG fraction. The size-dependent fatty acid and phospholipid composition suggests a different polarity of the large and small MFG fractions resulting from length and unsaturation differences in the fatty acids and polarity and structure differences in the phospholipids in each MFG size group. Such polarity differences could in turn change the affinity of the MFGM for proteins. This may explain, in part, the proteome differences between the large and small MFG fractions.

A previous study on the proteome of different sized globules in milk compared lactosomes (nanometer-sized and $\mathrm{Tg}$ depleted lipid-protein assemblies) to MFG. The number of proteins that was significantly increased between the large and small MFG fractions in our study (49 and 23, respectively), is very similar to what was found previously when comparing the proteome of regular MFG with that of lactosomes (Argov-Argaman et al., 2010). However, lactosomes are much smaller than the small MFG fraction in our study, and also do not carry a $\mathrm{Tg}$ core, so a further comparison of the proteome with their study was not done.

The PAT proteins, which are among the most abundant proteins in the MFGM, have been considered essential in lipid biogenesis (Ducharme and Bickel, 2008; Thiele and Spandl, 2008; Walther and Farese, 2009). In this study, ADFP and TIP47, 2 members of the PAT family of proteins, were identified in bovine MFGM. Interestingly, the abundance of these 2 proteins varied in different MFG size fractions. The ADFP preferentially localized in the large MFG fraction, whereas TIP47 localized in the small MFG fraction, which is consistent with a previous study (Wolins et al., 2005). The reason for this difference in distribution is, however, not clear. Accumulation of neutral lipids, fusion of small LD, or inhibition of $\mathrm{Tg}$ lipolysis have been suggested to play a role in creating or maintaining large LD (Ducharme and Bickel, 2008; Thiele and Spandl, 2008; Walther and Farese, 2009). The ADFP promoted the formation of large LD by inhibiting lipolysis in mammary epithelial cells (Russell et al., 2007), which thereby may explain the higher concentration of ADFP in the large MFG fraction. The concentration of GLYCAM1/PP3, another protein that could inhibit lipolysis (Sorensen et al., 1997), was also higher in the large MFG fraction (Table 5).

In the present study, a higher concentration of cytoplasmic vesicle proteins was observed in the large MFG fraction, which suggests a stronger association of cytoplasmic vesicle proteins with the membrane of large MFG/LD. Three groups of cytoplasmic vesicle proteins are present in higher concentration in the large MFG fraction (Table 5), including heat shock proteins (P19120, HSPA8; Q3T149, HSPB1; Q76LV1, HSP90AA1; Q0VCX2, HSPA5; and Q27965, HSPA1B), 14-3-3 proteins (P62261, YWHAE; P63103, YWHAZ; and P68250, YWHAB), and proteins from the Rab GTPase family (Q0IIG8, Rab 18; Q148J4, Rab 2A; and A1L528, Rab 1A). Two reasons for this difference are possible. First, larger LD may attract more membrane-bound vesicles on their surfaces because of the long-range London-Van der Waals and electrostatic forces (Wooding, 1971; Wu et al., 2000). Second, heat shock proteins, 14-3-3 proteins, and Rab 
GTPases, which have been previously reported in bovine and human MFGM (Reinhardt and Lippolis, 2006; Cavaletto et al., 2008), may play a role in stabilization of large MFG. Several heat shock proteins function as intracellular chaperones for other proteins. They play an important role in protein-protein interactions, such as folding and assisting in the establishment of proper protein conformation, and prevention of unwanted protein aggregation. The HSP70 (Q27965, HSPA1B) has been observed in intracellular LD in rat adipocytes where its suggested functions were stabilization of the membrane monolayer, transporting of nascent proteins to LD, and refolding of denatured proteins in the membrane layer (Jiang et al., 2007). Rab proteins are a group of proteins that play an important role in membrane trafficking, including vesicle formation, vesicle transportation, and membrane fusion (Mountjoy et al., 2008). Among the Rab proteins, Rab18 was observed in the surface of intracellular LD in HepG2 cells where it was involved in the apposition of ER and LD for transport of neutral lipid/fatty acids from ER to LD resulting in the growth of LD (Ozeki et al., 2005). Based on this existing knowledge of the function of these cytoplasmic vesicle proteins on growth of LD and stability of its membrane, we propose that the increase of these proteins in large MFG may increase intracellular stabilization of the LD membrane.

The enrichment in the large MFG fraction of nonmembrane-bound proteins, mainly cytoskeleton proteins (vimentin, plasmin L, and actin), as well as cytoskeleton-associated proteins (annexins and cofilin), suggests the involvement of these proteins in the heterogeneity in MFG size. The cytoskeleton, mainly microtubules, has previously been proposed to function in LD transport and fusion in a range of cell types, including epithelial cells of the mammary gland (Wu et al., 2000; Bostrom et al., 2005; Ducharme and Bickel, 2008). However, the presence of actin (microfilaments), vimentin (intermediate filaments), and their associated proteins (plasmin $\mathrm{L}$ and cofilin), instead of tubulin (microtubules), in this study could be indicative of the unexpected role of microfilaments and intermediate filaments in the growth and transport of LD in mammary epithelial cells. Actin was concentrated in the apical region of mammary epithelial cells and localized along the cytoplasmic surface of LD. Actin was suggested to help package LD with plasma membrane during budding to milk (Mather and Keenan, 1998). Beta-actin, the isoform also observed in this study, was shown to bind to intracellular LD in rat adrenocortical cells and adipocytes (Fong et al., 2001). Thus, one could assume that in the apical region of the cell, actin may bind to LD before its secretion and thereby regulate LD transport and growth, possibly by being involved in $\mathrm{LD}$ fusion as microtubule proteins do.
Unexpectedly, host defense proteins, mainly cathelicidins, differed between the large and small MFG fractions (Table 5). Cathelicidins have been thought to mainly originate from neutrophils, which are the major type of somatic cells in milk (Smolenski et al., 2011). Contamination of the large MFG fraction with neutrophils may therefore seem to be an obvious reason for the high level of cathelicidins. However, myeloperoxidase, the most abundant protein in neutrophils (Haegens et al., 2008), was not identified in the present study. In addition, the number of neutrophils should be low due to the 3 washing and centrifugation steps used to isolate the MFG fractions. Cathelicidin 1 ranked 15th based on the signal intensity of the 157 proteins identified in this study, which suggests that the origin of these cathelicidins might not only be neutrophils but also epithelial cells in the mammary gland. Cathelicidin-related antibacterial polypeptides have also been identified in the murine mammary gland (Murakami et al., 2005). However, to our knowledge, the expression of cathelicidins in bovine mammary gland has not been studied. Another possible reason for the selective accumulation of cathelicidins in MFGM could be due to their physical characteristics. Cathelicidins are normally positively charged and tend to fold into amphipathic structures (Zanetti, 2004), which could be the rationale for their binding to MFGM. Furthermore, this could also explain the altered affinity of cathelicidins to MFG of different sizes and therefore their higher content in the large compared with the small MFG fraction. However, this needs to be further elucidated.

Both cholesterol synthesis enzymes (LSS and NSDHL) were present in higher concentrations in the small MFG fraction (Table 6). Cholesterol is known to be an essential component for membrane integrity, permeability, rigidity, and functionality. Both LSS and NSDHL have been found to localize in intracellular LD in yeast and adipocytes (Caldas and Herman, 2003; Ohashi et al., 2003; Mullner et al., 2004; Goodman, 2009). These observations raised the possibility that LD could be the site of lipid/cholesterol synthesis rather than only being a central lipid depot (Caldas and Herman, 2003). It is possible that LD function as the site of lipid/cholesterol synthesis. If so, this could explain the higher concentration of LSS and NSDHL in the small MFG fraction because it requires relatively more membrane material, and therefore more cholesterol, to cover small MFG than large MFG. This is in agreement with the higher cholesterol content in smaller lipid droplets (Table 3). However, whether these enzymes in LD contribute to the synthesis of lipids needs to be further investigated.

In the present study, several hypotheses have been raised regarding different proteins and lipids that might be associated with MFG size. However, other reasons 
may also have led to these differences. Further targeted research is required to study these possible relations, and reveal the role of the observed components in MFG formation and secretion.

Aside from gaining a better understanding of lipid synthesis and secretion, the differences in protein and lipid composition between small and large MFG may also be interesting for producing dairy products with distinctive qualities. For example, butter with low SFA and low cholesterol could be produced from small MFG and large MFG, respectively. Also, specific functional proteins could be obtained from different sized MFG. For example, immune-active proteins from milk have been suggested as potential ingredients for functional foods (Zanetti, 2004).

\section{CONCLUSIONS}

The observations from this study clearly demonstrate the difference in protein and lipid composition of the membranes of the small and large MFG fractions. Our results on PAT proteins are in agreement with their previously reported role in MFG formation and secretion. In addition, our results for the first time suggest the importance of cytoplasmic vesicle proteins, cytoskeleton proteins, and cholesterol synthesis enzymes in MFG formation and secretion. Proteomics and lipidomics analysis provides us a more complete overview of the difference in different sized MFG fractions. In future, cell biology studies focusing on the proteins and lipids discussed in this paper, including their interaction, could further elucidate the processes underlying the difference in fat globule size, and thereby lead to a better understanding of MFG formation and secretion.

\section{ACKNOWLEDGMENTS}

This research was part of the Dutch Milk Genomics Initiative and the project "Melk op Maat," funded by Wageningen University (Wageningen, the Netherlands), the Dutch Dairy Association (NZO, Zoetermeer, the Netherlands), the cooperative cattle improvement organization CRV (Arnhem, the Netherlands), the Dutch Technology Foundation (STW, Utrecht, the Netherlands), the Dutch Ministry of Economic Affairs (the Hague, the Netherlands), and the Provinces of Gelderland (Arnhem, the Netherlands) and Overijssel (Zwolle, the Netherlands).

\section{REFERENCES}

Argov-Argaman, N., T. Mbogori, C. Sabastian, A. Shamay, and S. J. Mabjeesh. 2012. Hyperinsulinemic clamp modulates milk fat globule lipid composition in goats. J. Dairy Sci. 95:5776-5787.
Argov-Argaman, N., J. T. Smilowitz, D. A. Bricarello, M. Barboza, L. Lerno, J. W. Froehlich, H. Lee, A. M. Zivkovic, D. G. Lemay, S. Freeman, C. B. Lebrilla, A. N. Parikh, and J. B. German. 2010. Lactosomes: Structural and compositional classification of unique nanometer-sized protein lipid particles of human milk. J. Agric. Food Chem. 58:11234-11242.

Boersema, P. J., R. Raijmakers, S. Lemeer, S. Mohammed, and A. J. Heck. 2009. Multiplex peptide stable isotope dimethyl labeling for quantitative proteomics. Nat. Protoc. 4:484-494.

Bostrom, P., M. Rutberg, J. Ericsson, P. Holmdahl, L. Andersson, M. A. Frohman, J. Boren, and S. O. Olofsson. 2005. Cytosolic lipid droplets increase in size by microtubule-dependent complex formation. Arterioscler. Thromb. Vasc. Biol. 25:1945-1951.

Briard, V., N. Leconte, F. Michel, and M.-C. Michalski. 2003. The fatty acid composition of small and large naturally occurring milk fat globules. Eur. J. Lipid Sci. Technol. 105:677-682.

Caldas, H., and G. E. Herman. 2003. NSDHL, an enzyme involved in cholesterol biosynthesis, traffics through the Golgi and accumulates on ER membranes and on the surface of lipid droplets. Hum. Mol. Genet. 12:2981-2991.

Cavaletto, M., M. G. Giuffrida, and A. Conti. 2008. Milk fat globule membrane components-a proteomic approach. Adv. Exp. Med. Biol. 606:129-141.

Cohen, B. C., A. Shamay, and N. Argov-Argaman. 2015. Regulation of lipid droplet size in mammary epithelial cells by remodeling of membrane lipid composition-A potential mechanism. PLoS ONE 10:e0121645

Cox, J., and M. Mann. 2008. MaxQuant enables high peptide identification rates, individualized p.p.b.-range mass accuracies and proteome-wide protein quantification. Nat. Biotechnol. 26:1367-1372.

Cox, J., N. Neuhauser, A. Michalski, R. A. Scheltema, J. V. Olsen, and M. Mann. 2011. Andromeda: A peptide search engine integrated into the MaxQuant environment. J. Proteome Res. 10:1794-1805.

Dewettinck, K., R. Rombaut, N. Thienpont, T. T. Le, K. Messens, and J. V. Camp. 2008. Nutritional and technological aspects of milk fat globule membrane material. Int. Dairy J. 18:436-457.

Ducharme, N. A., and P. E. Bickel. 2008. Lipid droplets in lipogenesis and lipolysis. Endocrinology 149:942-949.

Folch, J., M. Lees, and G. H. Sloane Stanley. 1957. A simple method for the isolation and purification of total lipids from animal tissues. J. Biol. Chem. 226:497-509.

Fong, T. H., C. H. Wu, E. W. Liao, C. Y. Chang, M. H. Pai, R. J. Chiou, and A. W. Lee. 2001. Association of globular beta-actin with intracellular lipid droplets in rat adrenocortical cells and adipocytes. Biochem. Biophys. Res. Commun. 289:1168-1174.

Goodman, J. M. 2009. Demonstrated and inferred metabolism associated with cytosolic lipid droplets. J. Lipid Res. 50:2148-2156.

Guo, Y., T. C. Walther, M. Rao, N. Stuurman, G. Goshima, K. Terayama, J. S. Wong, R. D. Vale, P. Walter, and R. V. Farese. 2008 Functional genomic screen reveals genes involved in lipid-droplet formation and utilization. Nature 453:657-661.

Haegens, A., J. H. Vernooy, P. Heeringa, B. T. Mossman, and E. F. Wouters. 2008. Myeloperoxidase modulates lung epithelial responses to pro-inflammatory agents. Eur. Respir. J. 31:252-260.

Heid, H. W., and T. W. Keenan. 2005. Intracellular origin and secretion of milk fat globules. Eur. J. Cell Biol. 84:245-258.

Hörl, G., A. Wagner, L. K. Cole, R. Malli, H. Reicher, P. Ketzobeck, H. Köfeler, G. Höfler, S. Frank, J. G. Bogner-Strauss, W. Sattler, D. E. Vance, and E. Steyrer. 2011. Sequential synthesis and methylation of phosphatidylethanolamine promote lipid droplet biosynthesis and stability in tissue culture and in vivo. J. Biol. Chem. 286:17338-17350.

Huang, D. W., B. T. Sherman, and R. A. Lempicki. 2009. Systematic and integrative analysis of large gene lists using DAVID bioinformatics resources. Nat. Protoc. 4:44-57.

ISO-IDF. 2002a. Milk fat-Preparation of fatty acid methyl esters. ISO 15884:2002. International Dairy Federation, Brussels, Belgium.

ISO-IDF. 2002b. Milk fat-Determination of the fatty acid composition by gas-liquid chromatography. ISO 15885:2002. International Dairy Federation, Brussels, Belgium. 
Jensen, S. K., and K. N. Nielsen. 1996. Tocopherols, retinol, betacarotene and fatty acids in fat globule membrane and fat globule core in cows' milk. J. Dairy Res. 63:565-574.

Jiang, H., J. He, S. Pu, C. Tang, and G. Xu. 2007. Heat shock protein 70 is translocated to lipid droplets in rat adipocytes upon heat stimulation. Biochim. Biophys. Acta 1771:66-74.

Lopez, C., V. Briard-Bion, O. Ménard, E. Beaucher, F. Rousseau, J Fauquant, N. Leconte, and B. Robert. 2010. Fat globules selected from whole milk according to their size: Different compositions and structure of the biomembrane, revealing sphingomyelin-rich domains. Food Chem. 125:355-368.

Lopez, C., and O. Menard. 2011. Human milk fat globules: Polar lipid composition and in situ structural investigations revealing the heterogeneous distribution of proteins and the lateral segregation of sphingomyelin in the biological membrane. Colloids Surf. B Biointerfaces 83:29-41.

Lu, J., S. Boeren, S. C. de Vries, H. J. van Valenberg, J. Vervoort, and K. Hettinga. 2011. Filter-aided sample preparation with dimethyl labeling to identify and quantify milk fat globule membrane proteins. J. Proteomics 75:34-43.

Mather, I. H., and T. W. Keenan. 1998. Origin and secretion of milk lipids. J. Mammary Gland Biol. Neoplasia 3:259-273.

McManaman, J. L., and M. C. Neville. 2003. Mammary physiology and milk secretion. Adv. Drug Deliv. Rev. 55:629-641.

Mesilati-Stahy, R., H. Malka, and N. Argov-Argaman. 2012. Association of plasma insulin concentration to fatty acid distribution between milk fat and membrane synthesis. J. Dairy Sci. 95:17671775 .

Mesilati-Stahy, R., K. Mida, and N. Argov-Argaman. 2011. Size-dependent lipid content of bovine milk fat globule and membrane phospholipids. J. Agric. Food Chem. 59:7427-7435.

Mesilati-Stahy, R., U. Moallem, Y. Magen, and N. Argov-Argaman 2015. Altered concentrate to forage ratio in cows ration enhanced bioproduction of specific size subpopulation of milk fat globules. Food Chem. 179:199-205.

Michalski, M. C., J. Y. Gassi, M. H. Famelart, N. Leconte, B. Camier, M. Francquise, and J. Fauquant. 2003. The size of native milk fat globules affects physico-chemical and sensory properties of Camembert cheese. Lait 83:131-143.

Michas, G., R. Micha, and A. Zampelas. 2014. Dietary fats and cardiovascular disease: putting together the pieces of a complicated puzzle. Atherosclerosis 234:320-328.

Mountjoy, J. R., W. Xu, D. McLeod, D. Hyndman, and R. Oko. 2008 RAB2A: A major subacrosomal protein of bovine spermatozoa implicated in acrosomal biogenesis. Biol. Reprod. 79:223-232.

Mullner, H., D. Zweytick, R. Leber, F. Turnowsky, and G. Daum. 2004. Targeting of proteins involved in sterol biosynthesis to lipid particles of the yeast Saccharomyces cerevisiae. Biochim. Biophys. Acta 1663:9-13.

Murakami, M., R. A. Dorschner, L. J. Stern, K. H. Lin, and R. L. Gallo. 2005. Expression and secretion of cathelicidin antimicrobial peptides in murine mammary glands and human milk. Pediatr. Res. 57:10-15.
Neill, J. D. 2006. Knobil and Neill's Physiology of Reproduction. Page 3296. Vol. 1. 3rd ed. J. D. Neill, ed. Academic Press, Cambridge, MA.

Ohashi, M., N. Mizushima, Y. Kabeya, and T. Yoshimori. 2003. Localization of mammalian $\mathrm{NAD}(\mathrm{P}) \mathrm{H}$ steroid dehydrogenase-like protein on lipid droplets. J. Biol. Chem. 278:36819-36829.

Ozeki, S., J. Cheng, K. Tauchi-Sato, N. Hatano, H. Taniguchi, and T. Fujimoto. 2005. Rab18 localizes to lipid droplets and induces their close apposition to the endoplasmic reticulum-derived membrane. J. Cell Sci. 118:2601-2611.

Reinhardt, T. A., and J. D. Lippolis. 2006. Bovine milk fat globule membrane proteome. J. Dairy Res. 73:406-416.

Russell, T. D., C. A. Palmer, D. J. Orlicky, A. Fischer, M. C. Rudolph, M. C. Neville, and J. L. McManaman. 2007. Cytoplasmic lipid droplet accumulation in developing mammary epithelial cells: roles of adipophilin and lipid metabolism. J. Lipid Res. 48:1463-1475.

Smolenski, G. A., R. J. Wieliczko, S. M. Pryor, M. K. Broadhurst T. T. Wheeler, and B. J. Haigh. 2011. The abundance of milk cathelicidin proteins during bovine mastitis. Vet. Immunol. Immunopathol. 143:125-130.

Sorensen, E. S., L. K. Rasmussen, L. Moller, and T. E. Petersen. 1997. The localization and multimeric nature of component PP3 in bovine milk: purification and characterization of PP3 from caprine and ovine milks. J. Dairy Sci. 80:3176-3181.

Stringer, D. M., P. Zahradka, V. C. Declercq, N. R. Ryz, R. Diakiw, L. A. Burr, X. Xie, and C. G. Taylor. 2010. Modulation of lipid droplet size and lipid droplet proteins by trans-10, cis-12 conjugated linoleic acid parallels improvements in hepatic steatosis in obese insulin-resistant rats. Biochim. Biophys. Acta 1801:1375-1385.

Thiam, A. R., R. V. Farese Jr., and T. C. Walther. 2013. The biophysics and cell biology of lipid droplets. Nat. Rev. Mol. Cell Biol. 14:775-786.

Thiele, C., and J. Spandl. 2008. Cell biology of lipid droplets. Curr Opin. Cell Biol. 20:378-385.

Timmen, H., and S. Patton. 1988. Milk fat globules: Fatty acid composition, size and in vivo regulation of fat liquidity. Lipids 23:685689

Walstra, P., J. T. M. Wouters, and T. J. Geurts. 2005. Dairy Science and Technology. 2nd ed. Taylor \& Francis, Abington, UK.

Walther, T. C., and R. V. Farese Jr... 2009. The life of lipid droplets. Biochim. Biophys. Acta 1791:459-466.

Wolins, N. E., B. K. Quaynor, J. R. Skinner, M. J. Schoenfish, A. Tzekov, and P. E. Bickel. 2005. S3-12, Adipophilin, and TIP47 package lipid in adipocytes. J. Biol. Chem. 280:19146-19155.

Wooding, F. B. 1971. The mechanism of secretion of the milk fat globule. J. Cell Sci. 9:805-821.

Wu, C. C., K. E. Howell, M. C. Neville, J. R. Yates 3rd, and J. L. Mc Manaman. 2000. Proteomics reveal a link between the endoplasmic reticulum and lipid secretory mechanisms in mammary epithelial cells. Electrophoresis 21:3470-3482.

Zanetti, M. 2004. Cathelicidins, multifunctional peptides of the innate immunity. J. Leukoc. Biol. 75:39-48. 